\title{
Survey and Scan to BIM Model for the Knowledge of Built Heritage and the Management of Conservation Activities
}

\author{
Raffaella Brumana, Daniela Oreni, Luigi Barazzetti, Branka Cuca, \\ Mattia Previtali and Fabrizio Banfi
}

\begin{abstract}
Surveying a historic building means to measure, to detect and to analyse its geometries, its structural elements, the connections still existing between the different parts, in order to define its state of conservation, to make structural analysis and finally to plan a proper project of conservation, consolidation and reuse. The survey represents the first necessary moment for building's knowledge investigation. Nowadays, the wide use of tools and accurate surveying techniques makes it possible to achieve an adequate level of accuracy of information related to the buildings; BIM tools offer a great potential, in terms of both planning and evaluation of the entire knowledge and conservation process of an historical building, and in terms of its management and future maintenance. In particular, the BIM technologies allow the communication between data coming from different software, allowing a greater exchange of information between many actors. In recent years, the generative process of Building Information Modelling (BIM) oriented to the digitization of built heritage has been supported by the development of new commands modelling able to integrate the output data produced by laser scanner surveys (point clouds) in major modelling applications. Structural elements, such as vaulted historical systems, arches, decorations, architectural ornaments and wall partitions with variable cross sections, require higher levels of detail (LOD) and information (LOI) compared to the digitalization process of new buildings. Therefore, the structure of a BIM model aimed at representing existing and historical artefacts (HBIM) requires the definition of a new digital process capable of converting traditional techniques used for the management of new buildings to those suitable for creation of digital versions of historical buildings that are unique of their kind. The aim of this paper is to present the results of the ongoing researches and activities carried out on survey and HBIM model of historical buildings.
\end{abstract}

R. Brumana $\cdot$ D. Oreni $(\bowtie) \cdot$ L. Barazzetti $\cdot$ B. Cuca $\cdot$ M. Previtali $\cdot$ F. Banfi Architecture, Built Environment and Construction Engineering-ABC Department,

Politecnico di Milano, Milan, Italy

e-mail: daniela.oreni@polimi.it 


\section{Introduction}

This paper tries to make a synthesis of the different lessons learnt, related both to the positive and critical aspects concerning Historic BIM (HBIM) feasibility, sustainability and usefulness, and to the challenges of using HBIM for restoration and preservation activities. The theoretical and practical approach adopted, overcame the current BIM logic, based on sequential Level of Detail (LoD) that is typical of new buildings from simplex to complex (Volk et al. 2014; AEC (CAN) BIM Protocol; American Institute of Architects 2013), from the preliminary to the executive design (Nuovo Codice Appalti 2017). This choice was made in favour of the maximum precision and articulated description and representation of each component of the existing building, in order to derive the conservation project. The challenge was to obtain a cost-effective HBIM able to embody the complexity of each element of an existing historically important building (i.e. walls, pillars, vaults, beams, timbers). A NonUniform Rational Basis-Splines (NURBS) based parametric generative modelling process is here proposed in order to get sustainable rich modelling, able to match the related information, moving HBIM towards the actors. On the lesson learnt from this experience and many others, the process of updating the current codification criteria (UNI11337-2017) started with a draft proposal, stimulating a debate for the future of HBIM adoption.

\section{The Main Case Study: The Basilica of Collemaggio in L'Aquila}

The Basilica of Collemaggio was significantly damaged by the earthquake of Richter Magnitude 5.9 that had struck the town of L'Aquila (Central Italy) on 6 April 2009: the dome, the transept and triumphal arches collapsed with their pillars, and great damage occurred to the apses, to the pillars of the arched walls of the nave, and to the longitudinal north front with the 'Holy Door'. The Basilica is a Romanesque masterpiece characterized by a dense, fascinating history and different construction phases, which began in 1270 (Bartolomucci 2004). An important event called 'Festa della Perdonanza' is celebrated every year on 28 and 29 August, with the procession ceremony transferring the original Papal bull established by Pope Celestino V from the Municipality to the Holy Door of the Basilica. The result is an extraordinary, unique mix of tangible and intangible community values to be preserved and transferred to the future generations. Thus, the restoration project 'Ripartire da Collemaggio' (Restarting from Collemaggio) has been undertaken by ENIservizi with the aim of giving new hope to the L'Aquila citizens. The Superintendence Office carried on the restoration project, with the scientific support of the University of L'Aquila and the Sapienza University of Rome, under the coordination of the Politecnico di Milano. The challenge was to improve on one side the use of BIM tools for existing buildings (Oreni et al. 2013; Brumana et al. 2017), able to combine all the complexity 
of the geometrical shapes, and on the other the use of these tools for processes of built heritage conservation (Della Torre 2015). The HBIM has been carried on by integrating the surveying (Oreni et al. 2014) with the information coming from the historical and archive research and with the construction technology analysis. The aim was to support the following activities: (i) the design project, preservation and decision-making, (ii) the management of critical issues, regarding the conservation of material authenticity and construction techniques and (iii) the need to guarantee safety also in case of other potentially stronger earthquakes. Given these main goals of the project, the production of HBIM of the Basilica needed to take into account the complex morphology of the different ancient structures and their transformations along the centuries.

\section{From 3D Geometric Survey to HBIM: Generative Modelling}

The surveys of the Basilica (Barazzetti et al. 2015a, b) has been carried out to check the geometry of the whole damaged Basilica, the out of plumbs, the structural state of the art, in order to support the preservation plan. A geodetic network has been carried out to strengthen the clouds registry (Laser scanner Faro Focus (C)), and the $3 \mathrm{D}$ photogrammetric image block processing, covering all the vertical walls and the vaulted system.

The first draft release of 2D digital drawings (plans and vertical sections) was delivered starting from the information collected during on-site surveying campaigns (May 2013); the first HBIM drafted version was delivered in support of the preliminary steps of the design project (end of 2013) and to the definitive-executive steps (2014-15).

In the case of Collemaggio Basilica, the precondition was the reliability of the HBIM from the point of view of geometry and interoperability: every element of the Basilica was be linked and related to the different kinds of information, and to be managed by various actors (Barazzetti et al. 2016). Therefore, the HBIM has been addressed to manage the geometric richness and morphology acquired by the point clouds in order to support the following modelling phases. The modelling procedure developed had to be able to gather all the richness of information contained in the point clouds (Fig. 1).

Under the BIM tool technological aspect, parametric BIM models are generally managed for new construction processes; even the latest developments of parametric applications do not provide advanced tools, being time consuming for model generation. Therefore, different methods of modelling and representation of complex architectonical elements and managing of parametric BIM (Scans to NURBS) with multiple levels of details have been experimented with promising results, (Banfi 2016; Banfi et al. 2017). 


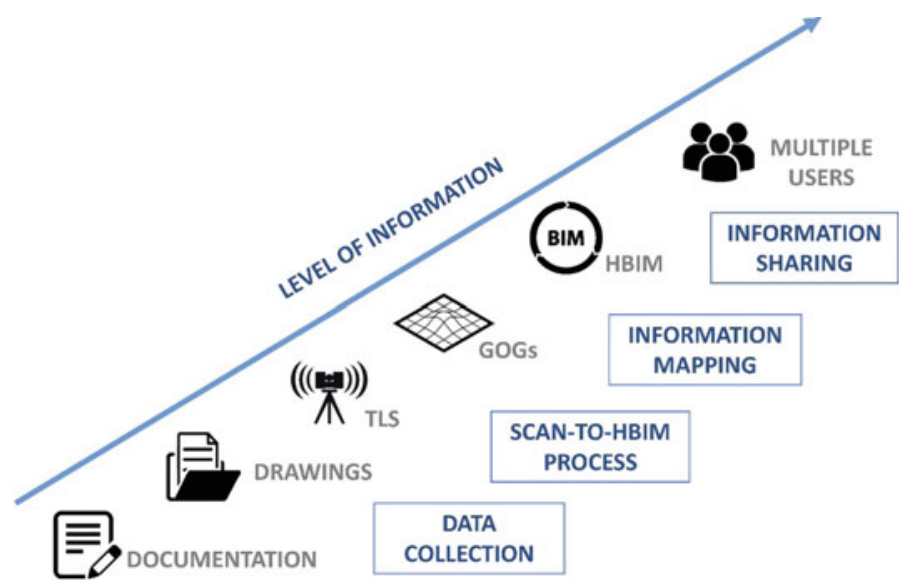

Fig. 1 The primary, secondary data sources and tools used for the generation of the HBIM model

A multi-slice-based wireframe model and/or cloud-based model have been adopted for each 3D parametric object, maintaining the morphologic richness and precision acquired by the surveying. A comprehensive overview of exiting procedures has been taken into account to define new processes and to boost the use of HBIM (Banfi 2016). The definition of the novel concept of 'Grade of Generation' (GOG 1-10) and Grade of Information (GOI), related to the object modelling, allows to enrich the logic of the traditional LOD sequence (100-500), defined by the AIA specifications (2013-2017), introducing as part of the process the method and functionalities adopted to generate the model objects themselves (Fig. 2). Starting from the cloud scans, the objects' models were generated within the CAD environment and within other modelling environments (such as MC Nell Rhinoceros (C)), in order to be managed further within the BIM tools (Banfi 2017).

In Fig. 3, the generative process from the first phase of processing is represented by the creation of accurate 3D parametric objects following the GOG 9 and GOG 10 generative modelling process and protocols implemented (Banfi 2019).

The study carried out on NURBS and geometric primitives led to improvements in the level of automation and accuracy of each element. Thanks to the combination of various advanced scan to BIM modelling requirements, and the proper use of generative profiles, the level of automation has passed from semi-automatic to automatic, avoiding long lead times and the relatively high costs involved in the digital 2D/3D representation. The generation of proper geometric primitives and the management of the generative digital process led to the creation of transmissible three-dimensional elements (Fig. 2). Clustering exchange formats (.dgw,.sat,.stp,.pts) made it possible to obtain and transfer 3D slices, profiles, control edges and complex shapes from a versatile 3D NURBS modeller (MC Neel Rhinoceros (C) to the most used comprehensive BIM application (Autodesk Revit (C)). 


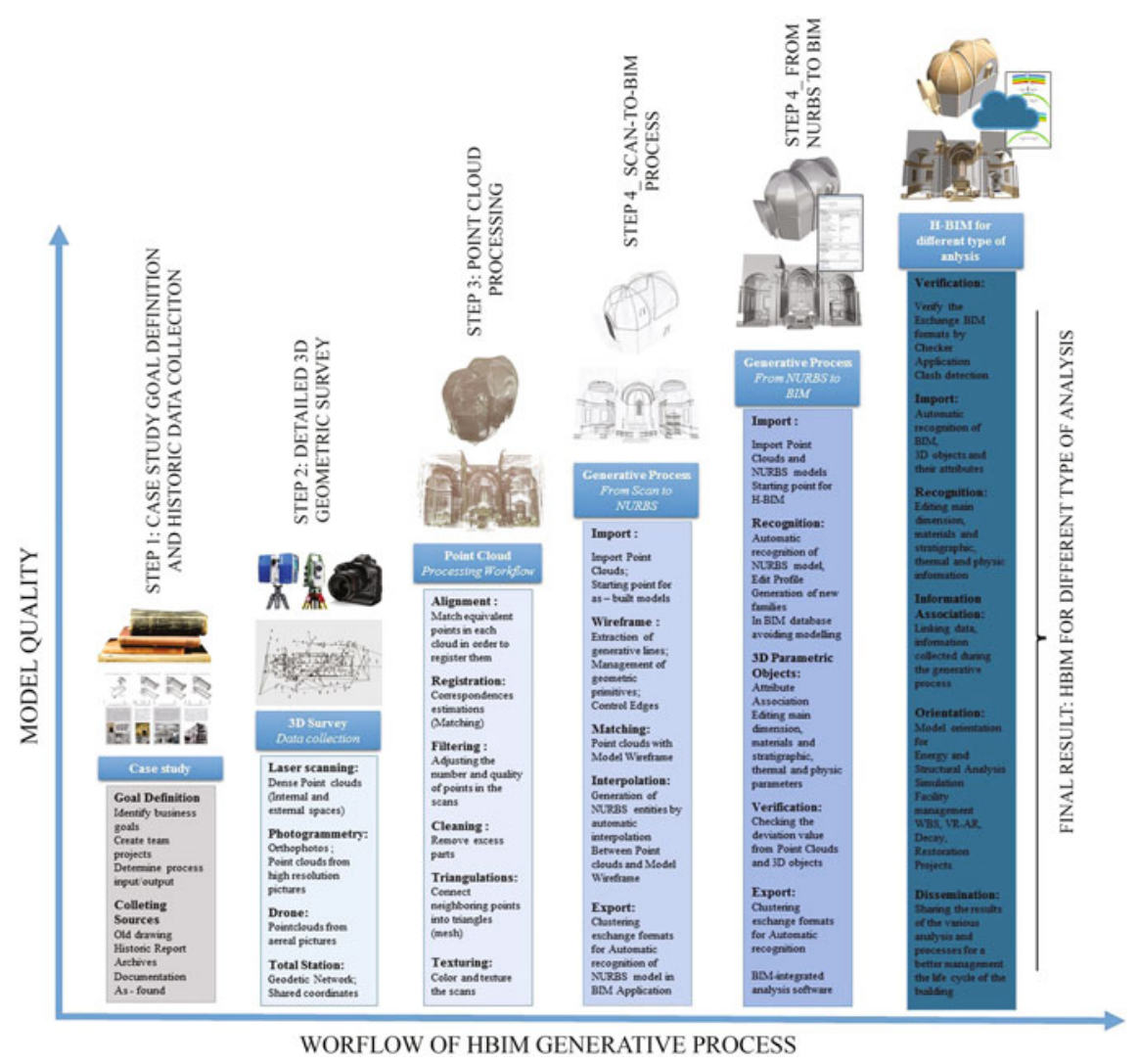

Fig. 2 The generative process applied to the HBIM of Basilica of Collemaggio. Source after Banfi (2019) holistic generative modelling process for HBIM

\section{HBIM as Building Site Tool to Share Different Data Among Actors}

The HBIM model was conceived to support operators, architects, structural engineers, and their activities: economic computation, construction site management, diagnostic analysis, design, construction tender and restoration itself. The adopted approach allows the HBIM to be updated and adapted by the different BIM actors in order to support the different phases: (i) models that provide a comparison and impact assessment of the simulation scenario of different solutions for decisions making about the crashed dome; (ii) conservation plan of the overall restoration design, progressively including the diagnostic analysis within the BIM (material analysis, surface decay analysis and preservation project) (Fig. 4); (iii)Finite Element Analysis (FEA) in support of the structural analysis, addressing the intervention on the damaged pillars, the walls and vaulted system; (Barazzetti et al. 2014; Crespi et al. 2016) 
POINTCLOUD
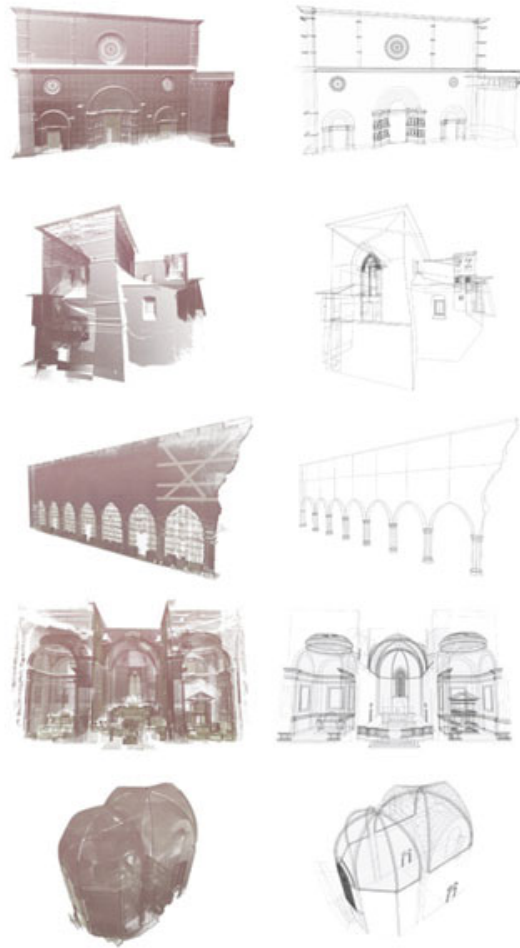

NURBS MODEL
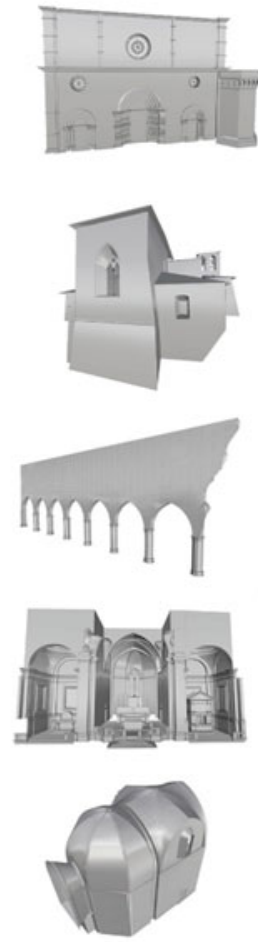

SCAN-10-BIM MODEL.
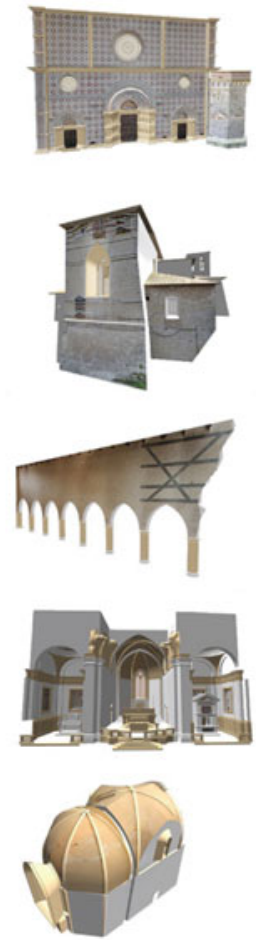

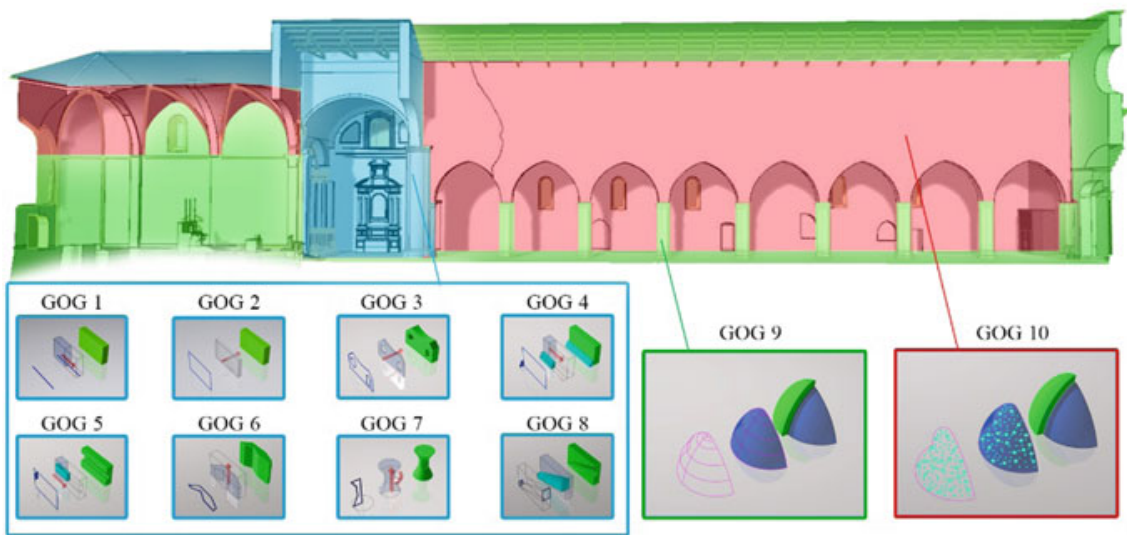

Fig. 3 The different GOGs applied during the generative process. Source Banfi (2019) holistic generative modelling process for HBIM 


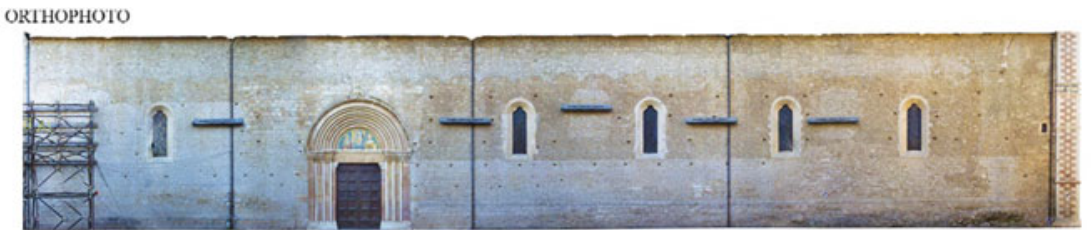

3D MAPPING

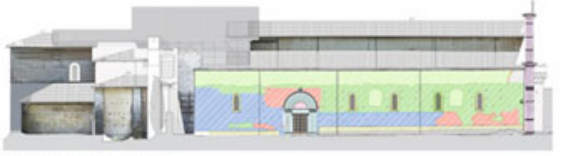

NURBS MODEL

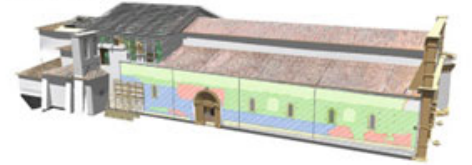

H-BLM FOR DECAY AREAS
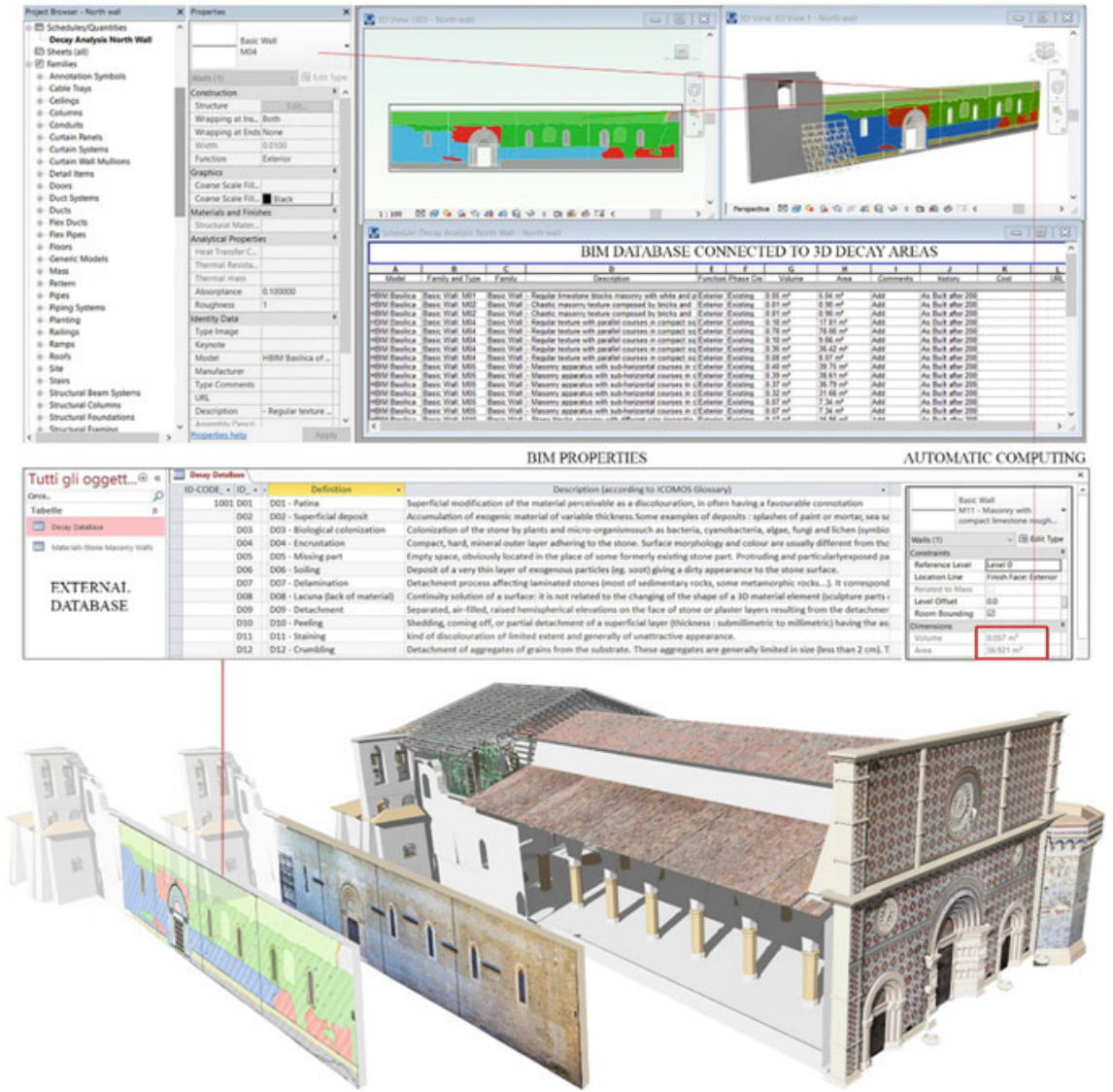

Fig. 4 The utility of HBIM for 3D mapping and the generation of specific BIM database related to the new type of information such as decay areas and stratigraphic information 
(iv) Work Breakdown Structure (WBS) of the restoration activities and the computational phase; (Brumana et al. 2018) (v) Construction Site Management (Co.Si.M) carried out on the HBIM adding machinery, construction site structures, simulation of the scaffoldings to manage the construction site and to simulate partitions in order to make the Basilica partially usable during the last phases of restoration; (vi) Virtual Reality/Cloud LIVEBIM management within Virtual Reality by I-devices for on site and touristic purposes.

During the Scan to HBIM process, different Level of Detail (LODs) have been defined and adopted in function of the different activities:

- HBIM conservation plan: 3D complex model of the damaged Basilica LoD500;

- HBIM design project and scenario simulation: LoD300 (i.e. solutions on the crashed dome and pillars);

- HBIM construction site management: simplification from LoD500 to LoD300 (complex to simplex);

- HBIM to WBS (supporting Work Breakdown Structures, list of the activities and metric-estimative computation): LoD500;

- HBIM preservation and maintenance plan: LoD 500;

- HBIM to FEA: LoD500;

- On site management and HBIM as-built updating (LoD500 and LoD500-300).

\section{Conclusions}

They remain a few open questions: did we manage the paradigm of HBIMs complexity linked to preservation challenges? In other words, can we boost the level of preservation of challenging aspects using BIM tools and interoperability? How to reach this goal in a time-cost-effective manner, thus encouraging a more systematic use of BIM by the public and private subjects? Which lacks and gaps have to be overcome in the future, besides the BIM modelling issues?

After different experiences, it is possible to argue that one HBIM challenges is represented by the structural analysis and decision-making towards the preservation aims. In theory, this result certainly represents an important step in the process linking HBIM complexity to the structural analysis domain. Given that the demolition and reconstruction of all the pillars was out of options requested by the Superintendence, this issue has become one of the main points of discussion among specialists, restorers and structural engineers. Authors here argue that in the case of single elements data management (such as the case of the pillars preservation), the use of HBIM has heavily contributed to support the preservation process. Structural intervention able to embody all the richness is gained from the HBIM model and it needs to be further investigated. During the restoration project and the on-site intervention regarding the Basilica of Collemaggio, many difficult compromises have been undertaken, between conservation and safety issues, causing also difficult choices when it was necessary to partially sacrifice functional authenticity of structural elements. In those 
cases, in order to enhance the level of preservation and to adopt softer measures of connection and reinforcement among structural elements (i.e. pillars, arches, walls, vaults, domes, trusses facades and wooden roof interventions), taking into account the tradition of their construction technologies, the HBIM model was fundamental tool for simulation of different scenarios to support better informed decision-making processes.

Acknowledgements The work on the Basilica of Collemaggio was supported by ENIservizi. The authors would like to thank P. Strada (ENIservizi), A. Garofalo (Soprintendenza ai Beni Architettonici e Paesaggistici per l'Abruzzo); Prof. A. Franchi, P. Crespi for the images taken during the restoration and BIM-FEA and M.A. Trani for the COSIM ones.

\section{References}

AEC (CAN) BIM Protocol (2014) Implementing Canadian BIM standards for the architectural, engineering and construction industry based on international collaboration

AIA (2013-2017) BIM forum, LOD specification. BIMForum 2013-2017. The level of development specification: for building information models, version: 2013-2017

American Institute of Architects (2013) AIA Document G202-2013: project building information modeling protocol form2

Banfi F (2016) Building information modelling - A novel parametric modeling approach based on 3D surveys of historic architecture. In: Ioannides M, et al. (eds) Digital heritage. Progress in cultural heritage: documentation, preservation, and protection. EuroMed 2016. Lecture notes in computer science, vol 10058. Springer, Cham

Banfi F (2017) Bim orientation: grades of generation and information for different type of analysis and management process. In: International archives of the photogrammetry, remote sensing and spatial information sciences, vol XLII-2-W5, pp 57-64

Banfi F, Fai S, Brumana R (2017) BIM automation: advanced modeling generative process for complex structures. In: ISPRS international conference on annals of the photogrammetry, remote sensing and spatial information sciences, vol IV-2-W2, pp 9-16

Banfi F (2019) Holistic generative modeling process for HBIM (Doctoral dissertation, Italy)

Barazzetti L, Brumana R, Oreni D, Previtali M, Roncoroni F (2014) UAV-based orthophoto generation in urban area: the Basilica of Santa Maria di Collemaggio in L'Aquila. In: Murgante B et al (eds) ICCSA 2014, part IV, LNCS 8582, 2014. @ Springer International Publishing, Switzerland 2014, pp 1-13

Barazzetti L, Banfi F, Brumana R, Previtali M (2015a) Creation of parametric BIM objects from point clouds using. Photogram Rec 30(152):339-362

Barazzetti L, Banfi F, Brumana R, Gusmeroli G, Previtali M, Schiantarelli G (2015b) Cloud-toBIM-to-FEM: structural simulation with accurate historic BIM from laser scans. Simul Model Pract Theory 57:71-87

Barazzetti L, Banfi F, Brumana R (2016) HBIM in the cloud. In: Digital heritage. progress in cultural heritage: documentation, preservation, and protection, EuroMed 2016, Springer, pp 104-115 (Werner Weber Award)

Bartolomucci C (2004) Santa Maria di Collemaggio. Interpretazione critica e problemi di conservazione. Palombi Editore, Roma

Brumana R, Della Torre S, Oreni D, Previtali M, Cantini L, Barazzetti L, Franchi A, Banfi F (2017) HBIM challenge among the paradigm of complexity, tools and preservation: the Basilica di Collemaggio 8 years after the earthquake (L'Aquila). In: International archives of the photogrammetry, remote sensing and spatial information sciences, vol XLII-2-W5, pp 97-104 
Brumana R, Della Torre S, Previtali M, Barazzetti L, Cantini L, Oreni D, Banfi F (2018) Generative HBIM-modeling to embody complexity. Surveying, preservation, site intervention. The Basilica di Collemaggio (L'Aquila). Appl Geomatics 10(4):545-567

Crespi PG, Franchi A, Giordano N, Scamardo MA, Ronca P (2016) Structural analysis of stone masonry columns of the Basilica S. Maria di Collemaggio. Eng Struct 129:81-90

Della Torre S (2015) Shaping tools for built heritage conservation: from architectural design to program and management. learning from Distretti culturali. In: Van Balen K et al (eds) Community involvement in heritage (reflections on cultural heritage theories and practices), pp 93-102

Della Torre S (2014) ICT per il miglioramento del processo conservativo. Nardini Editore, Firenze

G.U. 29/01/2008, n. 24 (and 2011 updates) Direttiva per la valutazione e la riduzione del rischio sismico del patrimonio culturale con riferimento alle norme tecniche per le costruzioni

Oreni D, Brumana R, Della Torre S, Banfi F, Barazzetti L, Previtali M (2014) Survey turned into HBIM: the restoration and the work involved concerning the Basilica di Collemaggio after the earthquake (L'Aquila). In: ISPRS annals of the photogrammetry, remote sensing and spatial information sciences, vol II/5, pp 267-273

Oreni D, Brumana R, Georgopoulos A, Cuca B (2013) HBIM for conservation and management of built heritage: towards a library of vaults and wooden bean floors. In: Grussenmeyer P (ed) ISPRS annals of photogrammetry, remote sensing and spatial information sciences, vol II-5/W1, Copernicus Publications, pp 215-221

Piegl LA, Tiller W (1997) The NURBS book. Springer

Volk R, Stengel J, Schultmann F (2014) Corrigendum to "Building information modeling (BIM) for existing buildings-literature review and future needs". Autom Constr 38:109-127. Automation in Construction, Vol 43, July 2014, 204 p

Nuovo Codice Appalti, L. 21/06/2017, n.96., found at https://www.gazzettaufficiale.it/eli/gu/2017/ 06/23/144/so/31/sg/pdf last accessed in June 2019

Open Access This chapter is licensed under the terms of the Creative Commons Attribution 4.0 International License (http://creativecommons.org/licenses/by/4.0/), which permits use, sharing, adaptation, distribution and reproduction in any medium or format, as long as you give appropriate credit to the original author(s) and the source, provide a link to the Creative Commons license and indicate if changes were made.

The images or other third party material in this chapter are included in the chapter's Creative Commons license, unless indicated otherwise in a credit line to the material. If material is not included in the chapter's Creative Commons license and your intended use is not permitted by statutory regulation or exceeds the permitted use, you will need to obtain permission directly from the copyright holder.

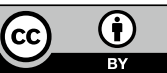

